\title{
PENGEMBANGAN AKHLAK PADA PENDIDIKAN ANAK USIA DINI
}

\author{
Junaidah ${ }^{1}$, Sovia Mas Ayu ${ }^{2}$ \\ ${ }^{1,2}$ Fakultas Tarbiyah dan Keguruan, UIN Raden Intan Lampung \\ 1 junaidah@radenintan.ac.id \\ ${ }^{2}$ sovia.masayu@radenintan.ac.id
}

\begin{abstract}
The study is aimed at developing morals indicator constructs in early childhood education. The method implemented in the study was research and development, developed by Borg \& Gall. The constructs of moral indicators validation was conducted by Early Childhood Education Science experts, and Islamic Education experts. The construct of moral indicators for Early Childhood Education was piloted by Early Childhood teachers. The results of the study showed that the moral indicators construct of Early childhood consisted of (4) four aspects, and four indicators of the simplicity, courage, wisdom, and justice.
\end{abstract}

Keywords: Morality, Early Childhood Education

\begin{abstract}
Abstrak
Penelitian ini bertujuan mengembangkan akhlak pada Pendidikan anak usia dini yaitu berupa konstruk indikator akhlak. Metode penelitian yang digunakan yaitu Research and Development (R\&D) yang dikembangkan oleh Borg \& Gall. Validasi konstruk indikator akhlak pada Pendidikan anak usia dini dilakukan oleh pakar Ilmu Pendidikan Anak Usia Dini, dan pakar Pendidikan Islam. Konstruk indikator akhlak pada Pendidikan Anak Usia Dini diujicobakan pada guru PAUD. Penelitian ini menghasilkan konstruk indikator akhlak yang terdiri dari (4) empat aspek, dan empat indikator kesederhanaan, keberanian, kebijaksanaan, dan keadilan.
\end{abstract}

Kata Kunci: Akhlak, Pendidikan Anak Usia Dini 


\section{PENDAHULUAN}

Manusia dilahirkan ke dunia ini dalam keadaan tidak berdaya dan tidak mengetahui satu apapun. Namun Allah Swt. memberikan potensipotensi dalam diri manusia berupa panca indera, yang dapat dikembangkan untuk mencapai tujuan akhir dari hikmah diciptakan-Nya manusia yaitu untuk beribadah kepada-Nya (QS. Adzariyat (51):56).

Salah satu potensi dasar manusia adalah kebutuhan untuk bersosialisasi dan berinteraksi. Sebagai makhluk sosial berarti manusia didalam hidupnya tidak dapat melepaskan diri dari pengaruh manusia lain (Setiadi, 2006). Keinginan manusia untuk berinteraksi dan hidup berkelompok dengan orang lain ini, membutuhkan kemampuan sosial dan pengelolaan emosi yang baik. Kemampuan sosial dan kemampuan pengelolaan emosi yang berhubungan dengan interaksi antar manusia tersebut diwujudkan dalam perilaku, dan dalam Islam disebut sebagai akhlak mulia.

Anak usia dini belajar melalui penglihatan kemudian mengikutinya. Apa yang dicontohkan orang-orang di luar dirinya, akan membekas dalam ingatan jangka panjang, dan akan dilakukan tanpa mengetahui baik buruknya. Jalaluddin (2000) mengatakan bahwa ketaatan kepada ajaran agama merupakan kebiasaan yang menjadi milik mereka yang dipelajari melalui orang tua dan guru mereka.

Masa kanak-kanak dengan usia 3-6 tahun disebut dengan masa prasekolah atau golden ages, merupakan masa bahagia dan masa memuaskan kreativitas, seperti bermain boneka, bercerita, bermain drama, menyanyi, menggambar dan lain sebagainya. Sebagai pendidik baik orang tua maupun guru bertanggung jawab terhadap tercapainya tujuan tersebut. Orang tua dan guru mempunyai kewenangan dalam mengarahkan perilaku anak sesuai yang diinginkan.

Tujuan Pendidikan Anak Usia Dini adalah mengembangkan seluruh potensi pada diri anak sehingga kelak mereka menjadi manusia yang utuh. Sedangkan tujuan Pendidikan Anak Usia Dini dalam pandangan Islam adalah memelihara, membantu pertumbuhan dan perkembangan fitrah manusia yang dimiliki oleh anak. Tujuan pendidikan ini harus tercapai dengan harapkan jiwa anak yang lahir dalam kondisi fitrah tidak terkotori oleh kehidupan duniawi.

Anak adalah manusia baru yang terlahir ke dunia tidak mengetahui apapun. Anak diajarkan bagaimana bertata krama, memiliki norma, etika dan berbagai hal tentang kehidupan. Anak juga diajarkan cara berkomunikasi 
dengan orang lain dan belajar memahami orang lain. Interaksi anak dengan benda dan orang lain diajarkan agar anak mampu mengembangkan kepribadian, watak, dan akhlak yang mulia.

Pengembangan nilai agama dan moral pada Lembaga Pendidikan anak usia dini masuk pada Kompetensi Inti-1 (KI-1), yaitu sikap spiritual. Kompetensi Inti ini kemudian dijabarkan dalam kompetensi dasar sikap spiritual, yaitu : mempercayai adanya Tuhan melalui ciptaan-Nya, dan menghargai diri sendiri, orang lain, dan lingkungan sekitar sebagai rasa syukur kepada Tuhan.

Kompetensi dasar tersebut kemudian tidak dirumuskan dalam bentuk indikator pencapaian perkembangan anak usia dini, tetapi diharapkan terlaksana secara tidak langsung dalam pembelajaran untuk Kompetensi Dasar pengetahuan dan keterampilan. Dapat disimpulkan bahwa pemerintah mengharapkan sikap sosial emosional atau akhlak anak usia dini terbentuk karena anak memiliki pengetahuan dan keterampilan yang baik.

Tidak adanya indikator pencapaian perkembangan aspek sikap spiritual tersebut, para guru kadang mengalami kesulitan dalam melaksanakan proses pembelajaran. Guru dituntut untuk mengembangkannya dalam kegiatan pengembangan aspek pengetahuan dan keterampilan.

Kurikulum 2013 untuk Pendidikan Anak Usia Dini terdiri dari beberapa program pengembangan, salah satunya adalah program pengembangan nilai agama dan moral. Kegiatan-kegiatan yang dijelaskan dalam kompetensi inti dan kompetensi dasar, bertujuan agar programprogram pengembangan yang telah dirumuskan dapat tercapai.

Sikap spiritual sebagai kompetensi inti Pendidikan Anak Usia Dini, yaitu : mempercayai adanya Tuhan melalui ciptaan-Nya, dan menghargai diri sendiri, orang lain, dan lingkungan sekitar sebagai rasa syukur kepada Tuhan. Nilai-nilai agama dan moral tersebut dalam Islam disebut sebagai akhlak mulia.

Penelitian yang telah dilakukan oleh Herawati (2017) menyimpulkan bahwa akhlak pada dasarnya mengajarkan bagaimana seseorang berhubungan dengan sang pencipta yaitu Allah SWT., dan bagaimana berhubungan dengan sesama manusia.

Muslich (2011) menyatakan bahwa seorang anak yang mendapatkan pendidikan akhlak yang baik mampu menghadapi dan menghindari pengaruh buruk dari lingkungan sekitarnya. Menurut Al-Ghazali (Yunus, 1992) bahwa akhlak yang baik itu hanya dapat dicapai dengan empat syarat yaitu; ilmu, amarah, syahwat (keinginan), dan keadilan. Amarah akan 
tunduk dengan ilmu, Sedangkan syahwat tunduk di bawah isyarat ilmu, yaitu isyarat akal dan syara'. Keadilan ialah menjaga syahwat dan amarah, supaya menurut isyarat dan syara'.

Pelaksanaan akhlak dalam kehidupan manusia adalah melaksanakan kewajiban-kewajiban, menjauhi segala larangan, memberikan hak kepada yang berhak, baik yang berhubungan dengan Allah maupun yang berhubungan dengan makhluk ciptaan-Nya, baik diri sendiri, orang lain dan lingkungan.

Pendidikan anak usia dini merupakan salah satu bentuk penyelenggaraan pendidikan yang menitik beratkan pada peletakan dasar pertumbuhan dan perkembangan (Hasan, 2009). Pertumbuhan dan perkembangan fisik (koordinasi motorik halus dan keras), kecerdasan (daya pikir daya cipta, kecerdasan emosi, kecerdasan spiritual), dan sosial emosional (sikap dan prilaku serta agama bahasa dan komunikasi) yang disesuaikan dengan tahap-tahap perkembangan anak usia dini.

Strategi dalam mendidik anak usia dini menurut Mansur (2007), dapat dilakukan, antara lain:

1. Mengidenfikasi serta menetapkan spesifikasi dan kualifikasi perubahan tingkah laku dan kepribadian anak usia dini sebagaimana yang diharapkan;

2. Memilih sistem pendekatan mendidik anak usia dini berdasarkan pandangan hidup;

3. Memilih dan menetapkan prosedur yang tepat; dan

4. Menetapkan norma-norma dan batas minimal keberhasilan sehingga dapat dijadikan pedoman oleh orang tua atau pendidik dalam melakukan evaluasi, yang selanjutnya akan dijadikan umpan balik buat penyempurnaan.

Standar kompetensi anak usia dini terdiri atas pengembangan aspekapek moral dan nilai-nilai agama, bahasa, kognitif, sosial, emosi dan kemandirian, fisik motorik, dan seni.

Aspek-aspek perkembangan pada anak usia dini, baik kecerdasan, perkembangan motorik, kemampuan fisik dan non fisik, maupun kemampuan spiritualnya, dapat berkembang optimal apabila mendapat dukungan dan stimulus yang tepat. Dukungan dan stimulus yang tepat, sangat mempengaruhi perkembangan anak berikutnya.

Karakteristik anak usia dini berbeda dengan orang dewasa, karena anak usia dini tumbuh dan berkembang dengan banyak cara dan berbeda. Hartati (2005) menyebutkan karakteristik anak usia dini antara lain memiliki rasa ingin tahu yang besar, merupakan pribadi yang unik, suka berfantasi dan 
berimajinasi, masa potensial untuk belajar, memiliki sikap egosentris, memiliki rentan daya konsentrasi yang pendek, dan merupakan bagian dari mahluk sosial.

Pendidikan Anak Usia Dini (PAUD) memiliki peranan penting dalam membentuk karakter anak yang berakhlak mulia, kreatif, inovatif dan kompetitif. Pendidikan Anak Usia Dini bukan sekedar meningkatkan pengetahuan dan keterampilan yang terkait dengan bidang keilmuan, tetapi lebih dalam adalah mempersiapkan anak agar kelak mampu menguasai berbagai tantangan di masa depan.

Pendidikan akhlak pada anak usia dini merupakan wahana pembinaan manusia menuju sosok paripurna yang berakhlak terpuji, bermoral baik, dan beriman serta bertakwa kepada Allah SWT. Oleh karena itu, Pendidikan akhlak sangat penting untuk ditanamkan sejak dini terutama dalam membentuk anak-anak sebagai benih bangsa yang diharapkan akhirnya hadir sebagai sosok utuh yang memberi sumbangsih yang berarti.

Al-Ghazali (2006) mengemukakan bahwa akhlak adalah sifat yang tertanam dalam jiwa yang menimbulkan beraneka ragam perbuatan dengan gampang dan mudah, tanpa memerlukan pemikiran dan pertimbangan. Aktivitas itu dilakukan dengan ikhlas semata-mata menuju ridha-Nya.

Akhlak merupakan prilaku yang timbul dari hasil perpaduan antara hati nurani, perasaan, pikiran, bawaan dan kebiasaan yang menyatu, membentuk suatu kesatuan akhlak yang dihayati dalam kenyataan hidup. Dari kelakuan itu lahirlah perasaan (moral) yang terdapat dalam diri manusia.

\section{METODE PENELITIAN}

Jenis Penelitian

Penelitian ini dikategorikan sebagai penelitian pengembangan yang merujuk pada prosedur pengembangan dari Borg \& Gall (1983). Penelitian ini bertujuan menghasilkan konstruk indikator akhlak pada Pendidikan anak usia dini.

Model Pengembangan $\mathrm{R}$ \& $\mathrm{D}$ pada penelitian ini dimodifikasi menjadi beberapa langkah, yaitu: (1) pengumpulan informasi; (2) perencanaan; (3) pengembangan produk awal; (4) uji coba pendahuluan; dan (5) revisi produk awal.

Waktu dan Tempat Penelitian

Penelitian ini dilakukan di 3 Taman Kanak-Kanak di Bandar Lampung. Uji coba dilaksanakan pada 20 guru Taman Kanak-Kanak di 3 
sekolah tersebut. Uji coba ini menghasilkan respon guru terhadap hasil pengembangan konstruk indikator akhlak.

Subjek Penelitian

Subjek dalam penelitian ini adalah guru Taman Kanak-Kanak atau Lembaga Pendidikan Anak Usia Dini. Sampel penelitian menggunakan teknik purposive sampling yaitu sebuah cara yang digunakan untuk mengambil sampel berdasarkan beberapa ketentuan (Borg \& Gall, 1983). Pertimbangan peneliti dalam menentukan sampel uji coba adalah karena guru Taman Kanak-Kanak di setiap sekolah sangat terbatas. Jumlah responden pada uji coba adalah 20 orang guru Taman Kanak-Kanak.

\section{Prosedur}

Penelitian pengembangan ini dilakukan dalam satu tahapan, yaitu tahap pengembangan Tahap pengembangan meliputi: (1) studi pendahuluan, meliputi pengumpulan informasi dan kajian teori; (2) perencanaan penelitian, meliputi perumusan tujuan dan memperkirakan waktu, dana, dan tenaga lapangan; (3) pengembangan disain awal, meliputi pengembangan draft awal dan revisi produk awal; (4) validasi pakar, meliputi uji keterbacaan dan kejelasan instrumen; dan (5) uji respon pengguna produk.

Data, Instrumen, dan Teknik Pengumpulan Data

Metode pengumpulan data menggunakan angket untuk validasi pakar dan angket uji respon pengguna produk. Instrumen angket validasi pakar diberi kode A dengan alternatif jawaban menggunakan skala 5, dan angket respon guru diberi kode B dengan alternatif jawaban menggunakan skala 5. Hasil validasi pakar dan angket respon guru, dicari nilai reratanya sebagai dasar penilaian akhir pengembangan konstruk indikator akhlak pada Pendidikan Anak Usia Dini.

\section{Teknik Analisis Data}

Uji validitas isi dari para pakar didasarkan pada nilai rata-rata angket (mean). Reliabilitas konstruk indikator Akhlak menggunakan formula Alpha Cronbach > 0,7 (Nunally, 1981). Butir dinyatakan baik apabila factor loading lebih besar dari 0,30. Presentasi komulatif menunjukkan cocok atau tidaknya faktor untuk dijadikan indikator jika jumlah presentasi > 50\% (Solimun, 2002).

Penilaian respon pengguna terhadap konstruk indikator akhlak menggunakan analisis terhadap mean score dengan simpangan baku ideal 
untuk setiap komponen yang dinilai mengacu pada model modifikasi Sudijono (2003) disajikan pada tabel 1.

Tabel 1. Acuan Pengubahan Nilai Skor menjadi Nilai Kategori

\begin{tabular}{|c|c|c|c|}
\hline No. & Rumus & $\begin{array}{c}\text { Rerata } \\
\text { Skor }\end{array}$ & Kategori \\
\hline 1. & $\mathrm{X}>\mathrm{X} \mathrm{i}+1,8 \times \mathrm{x} \mathrm{sb}_{\mathrm{i}}$ & $>4,2$ & Sangat Baik \\
\hline 2. & $\ddot{\mathrm{X}}_{\mathrm{i}}+0,6 \times \mathrm{x} \mathrm{sb}_{\mathrm{i}}<\mathrm{X} \leq \ddot{\mathrm{X}}_{\mathrm{i}}+1,8 \times \mathrm{xb}_{\mathrm{i}}$ & $>3,4-4,2$ & Baik \\
\hline 3. & $\ddot{\mathrm{X}}_{\mathrm{i}}-0,6 \times \mathrm{xb}_{\mathrm{i}}<\mathrm{X} \leq \ddot{\mathrm{X}}_{\mathrm{i}}+0,6 \times \mathrm{x} \mathrm{s}_{\mathrm{i}}$ & $>2,6-3,4$ & Cukup \\
\hline 4. & $\ddot{\mathrm{X}}_{\mathrm{i}}-1,8 \times \mathrm{xb}_{\mathrm{i}}<\mathrm{X} \leq \ddot{\mathrm{X}}_{\mathrm{i}}-0,6 \times \mathrm{xb}_{\mathrm{i}}$ & $>1,8-2,6$ & Kurang Baik \\
\hline 5. & $\mathrm{X} \leq \mathrm{X} \mathrm{i}-1,8 \mathrm{X} \mathrm{sb_{ \textrm {i } }}$ & $\leq 1,8$ & Sangat Kurang \\
\hline
\end{tabular}

(sumber: Sudijono, Anas, 2003).

Keterangan:

$\mathrm{X}_{\mathrm{i}}($ rerata ideal $)=1 / 2($ skor maksimum ideal + skor minimum ideal $)$ ideal)

$\mathrm{sb}_{\mathrm{i}}($ simpangan baku ideal $)=1 / 6($ skor maksimum ideal - skor minimum

$\mathrm{X}=$ skor empiris

Hasil rerata skor dan klasifikasi hasil pengembangan berdasarkan tabel 1 tersebut, dilanjutkan dengan kesimpulan penilaian terhadap konstruk indikator akhlak pada Pendidikan Anak Usia Dini, menggunakan standar penilaian yang ditampilkan pada tabel 2 .

Tabel 2. Hasil Konversi Skor menjadi Nilai Kategori

\begin{tabular}{|c|c|c|l|}
\hline No. & Rerata Skor & Kategori & \multicolumn{1}{|c|}{ Kesimpulan } \\
\hline 1. & $>4,2$ & Sangat Baik & Dapat dijadikan contoh \\
\hline 2. & $>3,4-4,2$ & Baik & Dapat digunakan tanpa perbaikan \\
\hline 3. & $>2,6-3,4$ & Cukup & $\begin{array}{l}\text { Dapat digunakan dengan sedikit } \\
\text { perbaikan }\end{array}$ \\
\hline 4. & $>1,8-2,6$ & Kurang Baik & $\begin{array}{l}\text { Dapat digunakan dengan banyak } \\
\text { perbaikan }\end{array}$ \\
\hline 5. & $\leq 1,8$ & Sangat Kurang & Belum dapat digunakan \\
\hline
\end{tabular}

(sumber: Mardapi, Djemari, 2008).

\section{PEMBAHASAN}

Pengembangan akhlak pada Pendidikan anak usia dini dilakukan dengan melakukan beberapa prosedur kegiatan yang tersusun secara 
sistematis dimulai dengan kajian teoritik, empirik, dan kegiatan survey lapangan sehingga menghasilkan konsep berupa konstruk indikator akhlak pada Pendidikan anak usia dini.

Studi pendahuluan pengembangan awal indikator akhlak didiskusikan dengan guru Pendidikan Anak Usia Dini, dan pakar bidang Pendidikan Anak Usia Dini. Hasil diskusi tersebut dan berdasarkan kajian teori, disusun draft awal konstruk indikator akhlak.

Akhlak sebagai gambaran dari iman seseorang yang ditunjukkan dalam bentuk perilaku, maka draft awal konstruk akhlak mengacu pada akhlak yang diajarkan oleh Luqman kepada anaknya ialah : (1) Akhlak anak kepada Allah SWT.; (2) Akhlak anak kepada orang tua; (3) Akhlak anak kepada orang lain; dan (4) Akhlak anak pada diri sendiri (Daradjat, 1995).

Akhlak kepada Allah, dapat diartikan sebagai sikap atau perbuatan yang dilakukan manusia sebagai makhluk ciptaan-Nya. Menurut Azmi (2006) alasan manusia berakhlak kepada Allah antara lain; pertama, karena Allah yang menciptakan manusia; Kedua, karena Allah yang memberikan perlengkapan panca indra berupa pendengaran, penglihatan, akal pikiran, dan hati sanubari; Ketiga, Allah yang telah menyediakan berbagai bahan dan sarana yang diperlukan bagi kelangsungan hidup manusia; Keempat, Allah yang telah memuliakan manusia dengan diberikan kemampuan menguasai daratan dan lautan.

Akhlak kepada sesama manusia dapat dikelompokkan menjadi akhlak kepada orang tua dan akhlak kepada orang lain. Alasan manusia berakhlak baik kepada sesama manusia khususnya sesama muslim karena bersaudara (QS. An-Nisaa (4):59).

Akhlak terhadap diri sendiri diwujudkan dengan memelihara kesucian diri, menutup aurat, jujur dalam perkataan dan perbuatan, ikhlas, sabar, rendah hati, malu, tidak melakukan perbuatan jahat, menjauhi dengki, menjauhi dendam, berlaku adil terhadap orng lain, dan menjauhi segala perrbuatan sia-sia (Azmi, 2006).

Akhlak merupakan bentuk jamak dari khuluq/perbuatan-perbuatan, yaitu keadaan jiwa yang mendorong seseorang untuk melakukan perbuatanperbuatan tanpa difikirkan dan diperhitungkan sebelumnya (Miskawaih, 2010).

Perbuatan-perbuatan atau akhlak tersebut, menurut konsep akhlak Miskawaih (2010) dibangun melalui empat induk keutamaan akhlak, yaitu: (1) al-'Iffah (kesederhanaan); (2) al-Syaja'ah (keberanian); (3) al-Hikmah (kebijaksanaan); dan (4) al-'Adalah (keadilan).

Al-'Iffah (kesederhanaan) adalah terdidiknya daya syahwat dengan pendidikan akal dan syariat. Dimensi al-'Iffah (kesederhanaan) ini dapat 
tertanam dalam diri manusia melalui pembiasaan semenjak kecil. Hal-hal yang dapat menumbuhkan al-'Iffah (kesederhanaan) dalam diri seseorang, yaitu: iman dan takwa, pernikahan, dan rasa malu.

Al-Syaja'ah atau keberanian adalah salah satu ciri yang dimiliki seseorang yang istiqamah berjuang di jalan Allah. Keberanian yang dimaksud bukan keberanian tanpa dasar, tapi keberanian melakukan dan menegakkan kebenaran berdasarkan nilai-nilai agama.

Miskawaih (2010) menyebutkan 9 (sembilan) karakteristik alsyaja'ah (keberanian) yang dimiliki seorang, antara lain: (1) jiwa besar Ikibar al-nafs; (2) pantang mundur /al-najdah; (3) ketenangan /'idzmu alhimmat; (4) keuletan/al-tsabat; (5) kesabaran/al-shabr; (6) murah hati/alhilm; (7) menahan diri/adam al-thaisy; (8) keperkasaan/al-syahamat; dan (9) mempunyai daya tahan yang besar/gemar bekerja keras/ihtimal al-kadd. Al-Hikmah (kebijaksanaan) adalah kondisi jiwa untuk memahami yang benar dari yang salah pada semua perilaku yang bersifat ikhtiar (pilihan). Sayyid Quthb (t.t) mengisyaratkan hal itu dalam tafsirnya bahwa hikmah adalah kemampuan meletakkan segala urusan di tempatnya yang benar dan menimbangnya dengan timbangan yang tepat, serta mendapatkan penyelesaian segala urusan dan petunjuk yang jelas.

Hikmah sebagai akhlak utama menurut al-Ghazali (2006) adalah kemampuan seseorang mengendalikan diri dari hawa nafsu. Hawa nafsu dalam diri meliputi amarah dan nafsu syahwat. Kemampuan mengendalikan hawa nafsu tersebut akan mengantarkan manusia menuju kebahagiaan dan keberhasilan dalam hidup.

Al-'Adalah (keadilan) dalam pandangan al-Ghazali (2006) adalah keberhasilan manusia atas perbuatannya, dan manusia akan bertanggung jawab melakukannya. Keadilan adalah kondisi dan kekuatan jiwa untuk menghadapi emosi dan syahwat serta menguasainya atas dasar kebijaksanaan, dan mengendalikannya sesuai dengan kebutuhan.

Hasil validasi pakar atau kesepakatan pakar diperoleh masukan mengenai indikator, keterbacaan butir, penggunaan bahasa dan tanda baca, metode penulisan, dan susunan tiap dimensi akhlak. Kegiatan ini juga dilakukan untuk memvalidasi produk berupa konstruk indikator akhlak pada Pendidikan Anak Usia Dini. Hasil validasi pakar dianalisis secara deskriptif untuk melihat mean scorenya. Hasil penilaian para pakar disajikan pada tabel 3. 
Tabel 3. Hasil Penilaian Indikator Akhlak Pada Pendidikan Anak Usia Dini

\begin{tabular}{|c|c|c|c|c|c|}
\hline No. & $\begin{array}{c}\text { Aspek } \\
\text { Akhlak }\end{array}$ & Indikator & Rerata & Kriteria & $\begin{array}{c}\text { Rerata/ } \\
\text { Aspek }\end{array}$ \\
\hline \multirow{4}{*}{1.} & \multirow{4}{*}{$\begin{array}{c}\text { Akhlak } \\
\text { Kepada Allah } \\
\text { SWT. }\end{array}$} & Kesederhanaan & 5,00 & $\begin{array}{l}\text { Sangat } \\
\text { baik }\end{array}$ & \multirow{4}{*}{4,875} \\
\hline & & Keberanian & 4,83 & $\begin{array}{c}\text { Sangat } \\
\text { baik }\end{array}$ & \\
\hline & & Kebijaksanaan & 4,67 & $\begin{array}{c}\text { Sangat } \\
\text { baik }\end{array}$ & \\
\hline & & Keadilan & 5,00 & $\begin{array}{l}\text { Sangat } \\
\text { baik }\end{array}$ & \\
\hline \multirow{4}{*}{2.} & \multirow{4}{*}{$\begin{array}{c}\text { Akhlak } \\
\text { Kepada Orang } \\
\text { Tua }\end{array}$} & Kesederhanaan & 5,00 & $\begin{array}{l}\text { Sangat } \\
\text { baik }\end{array}$ & \multirow{4}{*}{4,79} \\
\hline & & Keberanian & 5,00 & $\begin{array}{c}\text { Sangat } \\
\text { baik }\end{array}$ & \\
\hline & & Kebijaksanaan & 4,33 & $\begin{array}{c}\text { Sangat } \\
\text { baik }\end{array}$ & \\
\hline & & Keadilan & 4,83 & $\begin{array}{c}\text { Sangat } \\
\text { baik }\end{array}$ & \\
\hline \multirow{4}{*}{3.} & \multirow{4}{*}{$\begin{array}{c}\text { Akhlak } \\
\text { Kepada Orang } \\
\text { Lain }\end{array}$} & Kesederhanaan & 5,00 & $\begin{array}{l}\text { Sangat } \\
\text { baik }\end{array}$ & \multirow{4}{*}{4,833} \\
\hline & & Keberanian & 4,67 & $\begin{array}{l}\text { Sangat } \\
\text { baik }\end{array}$ & \\
\hline & & Kebijaksanaan & 4,83 & $\begin{array}{c}\text { Sangat } \\
\text { baik }\end{array}$ & \\
\hline & & Keadilan & 4,83 & $\begin{array}{c}\text { Sangat } \\
\text { baik }\end{array}$ & \\
\hline \multirow{4}{*}{4.} & \multirow{4}{*}{$\begin{array}{c}\text { Akhlak } \\
\text { Kepada Diri } \\
\text { Sendiri }\end{array}$} & Kesederhanaan & 4,83 & $\begin{array}{c}\text { Sangat } \\
\text { baik }\end{array}$ & \multirow{4}{*}{4,79} \\
\hline & & Keberanian & 4,83 & $\begin{array}{l}\text { Sangat } \\
\text { baik }\end{array}$ & \\
\hline & & Kebijaksanaan & 4,67 & $\begin{array}{c}\text { Sangat } \\
\text { baik }\end{array}$ & \\
\hline & & Keadilan & 4,83 & $\begin{array}{l}\text { Sangat } \\
\text { baik }\end{array}$ & \\
\hline 5. & \multicolumn{4}{|c|}{ Rerata Total } & 4,822 \\
\hline
\end{tabular}

Penilaian para pakar terhadap konstruk indikator akhlak yang dikembangkan menunjukkan bahwa seluruh indikator akhlak yang 
dikembangkan dalam penelitian ini memiliki kriteria sangat baik. Oleh karena itu, berdasarkan rerata validasi pakar, dapat dikatakan bahwa kategori pengembangan akhlak sangat baik, memadai, dan dapat dijadikan contoh. Setelah dilakukan revisi berdasarkan saran dan pendapat para pakar, konstruk hipotetik Akhlak tetap disusun dalam empat aspek dan empat indikator untuk setiap aspek.

Hasil validasi dan setelah revisi konstruk indikator akhlak sesuai masukan para pakar tersebut, kemudian diberikan kepada 20 guru Pendidikan Anak Usia Dini untuk memberikan respon terhadap konstruk indikator yang telah dikembangkan. Hasil respon guru disajikan pada tabel 4.

Tabel 4. Hasil Respon Guru Terhadap Konstruk Indikator Akhlak

\begin{tabular}{|c|l|c|}
\hline No. & \multicolumn{1}{|c|}{ Aspek yang dinilai } & Rerata skor \\
\hline 1. & $\begin{array}{l}\text { Kejelasan prosedur/langkah- } \\
\text { langkah pengembangan } \\
\text { akhlak }\end{array}$ & 3,83 \\
\hline 2. & Kejelasan/komunikatif bahasa & 3,50 \\
\hline 3. & Komperhensif aspek akhlak & 3,33 \\
\hline 4. & $\begin{array}{l}\text { Komperhensif indikator } \\
\text { akhlak }\end{array}$ & 3,33 \\
\hline 5. & Kepraktisan konstruk akhlak & 3,50 \\
\hline 6. & Rerata Total & $\mathbf{3 , 4 9 8}$ \\
\hline
\end{tabular}

Hasil respon guru terhadap konstruk indikator yang telah dikembangkan menunjukkan bahwa konstruk indikator akhlak aspek kejelasan prosedur dan langkah-langkah pengembangan indikator dalam kategori baik, aspek kejelasan/komunikatif Bahasa yang digunakan pada indikator kategori baik, respon guru terhadap komprehensif aspek akhlak secara konstruk dengan kategori cukup, komprehensif indikator akhlak juga kategori cukup, sedangkan untuk aspek kepraktisan konstruk akhlak yang dikembangkan dengan kategori baik. Berdasarkan hasil jawaban respon guru tersebut, maka dapat diberikan kesimpulan bahwa respon guru terhadap pengembangan konstruk indikator akhlak pada Pendidikan Anak Usia Dini dapat digunakan tanpa perbaikan.

\section{PENUTUP}

Berdasarkan hasil penelitian dan analisis data, dapat disimpulkan bahwa konstruk indikator akhlak pada Pendidikan anak usia dini yang dikembangkan meliputi aspek Akhlak kepada Allah SWT., aspek Akhlak pada orang tua, aspek Akhlak pada orang lain, dan aspek Akhlak pada diri sendiri. 4 (empat) aspek tersebut kemudian dikembangkan menjadi 4 
(indikator) untuk masing-masing aspek, terdiri dari kesederhanaan, keberanian, kebijaksanaan, dan keadilan. Setiap aspek terdiri dari 4 indikator dengan 2 variabel observed. Karakteristik konstruk indikator Akhlak dibuktikan dengan nilai mean semua aspek dan indikator diatas 4,2.

Berdasarkan hasil uji respon guru Pendidikan Anak Usia Dini, konstruk indikator Akhlak pada Pendidikan Anak Usia Dini dapat digunakan walupun harus dilakukan perbaikan. Konstruk Indikator Akhlak pada Pendidikan Anak Usia Dini dapat dikembangkan lebih lanjut melalui ujicoba terbatas dan ujicoba skala luas sampai tahap diseminasi. Hal ini perlu dilakukan agar terbentuk konstruk indikator Akhlak yang layak dan lebih baik.

\section{DAFTAR PUSTAKA}

Al-Ghazali. 2006. Ihya ulum al-diin. Haramain, Al-Qohirah.

Azmi, Muhammad. 2006. Pembinaan akhlak anak usia pra sekolah. Buluka. Yogyakarta.

Borg, W.R.A., \& Gall, M.D. 1983. Educational research and introduction. $\left(4^{\text {th }} e\right.$ d.). Longman, New York.

Daradjat, Zakiyah. 1995. Pendidikan Islam Dalam Keluarga Dan Sekolah. CV. Ruhama. Bandung.

Hartati, Sofia. 2005. Perkembangan belajar pada anak usia dini. Dirjen Dikti, Jakarta.

Hasan, Maemunah. 2009. PAUD (pendidikan anak usia dini). Diva Press (Anggota IKAPI). Yogyakarta.

Herawati. 2 Oktober 2018. Pendidikan akhlak bagi anak usia dini. Jurnal.arraniry.ac.id.

Jalaluddin. 2000. Psikologi agama. PT. Rineka Cipta, Jakarta.

Mansur. 2007. Pendidikan anak usia dini dalam Islam. Pustaka Pelajar, Yogyakarta.

Miskawaih, I. 2010. Tahdzib al-akhlak. Islamic book. WS. Online.

Muslich, Masnur. 2011. Pendidikan karakter menjawab tantangan krisis multidimensional. Bumi Aksara, Jakarta.

Nunally, J.C. 1981. Psychometric theory $\left(3^{\text {rd }}\right)$. McGraw-Hill Book Company, New York.

Setiadi, Elly M. 2006. Ilmu sosial dan budaya dasar. Prenada Media Group, Jakarta.

Solimun. 2002. Structural equation modeling (SEM), lisrel, dan amos. Fakultas MIPA Universitas Brawijaya, Malang.

Sudijono, Anas. 2003. Pengantar statistik pendidikan. Raja Grafindo, Jakarta.

Yunus, Muhammad. Sejarah pendidikan Islam. Hidakarya Agung, Jakarta. 